\title{
Using regulation to limit salt intake and prevent non- communicable diseases: lessons from South Africa's experience
}

\author{
Jenny Claire Kaldor ${ }^{1, *}$, Anne Marie Thow ${ }^{2}$ and Hettie Schönfeldt ${ }^{3,4}$
}

${ }^{1}$ Sydney Law School, The University of Sydney, Law School Building (F10), Eastern Avenue, Camperdown, NSW 2006, Australia: ${ }^{2}$ Menzies Centre for Health Policy, The University of Sydney, Sydney, NSW, Australia: ${ }^{3}$ Institute of Food, Nutrition and Well-being, University of Pretoria, Pretoria, South Africa: ${ }^{4}$ Department of Animal and Wildlife Sciences, University of Pretoria, Pretoria, South Africa

Submitted 31 March 2018: Final revision received 7 September 2018: Accepted 12 October 2018: First published online 27 December 2018

\begin{abstract}
Objective: To analyse the policy process for the South African regulation setting upper limits for salt in thirteen commonly consumed food categories, to inform future policy action for prevention of non-communicable diseases.

Design: Semi-structured interviews ( $n$ 10) were conducted with key stakeholders from government, academia, non-governmental organisations and the food industry. Interviewees were asked about the content, context, process and actors involved in developing the regulation. Data were analysed according to Walt and Gilson's health policy analysis triangle.

Setting: South Africa.

Participants: Key actors and stakeholders in the policy process to develop the salt regulation.

Results: The regulation was a response to research establishing the effectiveness of food supply interventions and to a shared perception that government regulation was the quickest way to address the problem of salt overconsumption. While the regulations were developed through a consultative process, food industry stakeholders perceived the consultation as inadequate. Implementation is currently underway, supported by a health promotion programme. Monitoring and enforcement were identified as the most likely challenges due to capacity constraints.

Conclusions: Comprehensive mandatory salt limits are an innovative approach to food reformulation. Factors that enabled regulation included robust scientific evidence, strong political and bureaucratic leadership, and the pragmatic use of existing regulatory instruments. The main challenges identified were disagreement over the appropriate nature and extent of food industry participation, and monitoring and enforcement challenges due to capacity constraints.
\end{abstract}

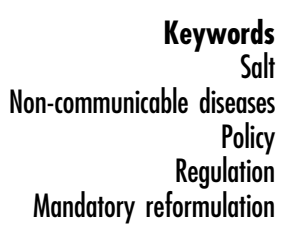

Non-communicable diseases (NCD) are now the leading cause of mortality worldwide and represent a major public health challenge ${ }^{(1)}$. These include CVD, diabetes, cancer and chronic respiratory diseases, which share four underlying modifiable risk factors: tobacco use, the harmful use of alcohol, physical inactivity and unhealthy diets. Unhealthy diets are high in sodium/salt, sugar, fats (especially trans and saturated fats) and overall energy, and low in fruit, vegetables, fibre and whole grains ${ }^{(2)}$. There is global commitment to introducing policies to improve consumers' ability to make healthier choices and to make the composition of the food supply healthier (reformulation) $^{(3,4)}$. Reformulation refers to changing the composition of processed foods to make them healthier: usually, reducing their salt, sugar or fat content, and/or their overall energy density ${ }^{(5)}$. The WHO has endorsed reformulation as a strategy to reduce consumption of salt, saturated fats and trans fats ${ }^{(3)}$. However, although reformulation is a clear policy goal, questions remain as to the best way of achieving it ${ }^{(6,7)}$.

In terms of policy options, the choice is usually presented as 'voluntary' $v$. 'mandatory' reformulation ${ }^{(8)}$. Both approaches tend to be government-led, but mandatory reformulation involves the use of law while 'voluntary' refers to companies taking action that is encouraged, assisted or overseen by government. To date, governments around the world have preferred voluntary approaches to reformulation ${ }^{(9,10)}$, occupying a broad 
regulatory spectrum from platforms for stakeholder dialogue to public-private partnerships ${ }^{(11,12)}$. A good example of the latter was the UK's successful efforts to reduce salt in the food supply during 2003-2011, usually described as a government-led, voluntary scheme ${ }^{(13,14)}$. However, voluntary reformulation is criticised by public health and regulatory experts who argue that, without stronger government oversight, progress is slow or ineffective, and genuine food supply change hampered by conflicts of interest ${ }^{(15-21)}$. Mandatory reformulation, they argue, would be the more effective approach ${ }^{(8,22)}$

Mandatory reformulation tends to be implemented through government laws or regulations specifying permissible upper limits of particular nutrients or ingredients in particular foods ${ }^{(23)}$. Over the past two decades, the number of jurisdictions implementing such regulations ('mandatory nutrient limits') has grown significantly, to twenty-four ${ }^{(24)}$. Mandatory limits have been effective in reducing trans fats in the food supply ${ }^{(25)}$, prompting calls for similar mandatory approaches to be used for other NCD-associated nutrients, including salt ${ }^{(26,27)}$. However, while eleven jurisdictions have implemented mandatory salt limits, to date these have not applied across the food supply but only to individual food categories.

High salt intake is a risk factor for hypertension and CVD, causing an estimated 1.7 million deaths worldwide in $2010^{(1)}$. The WHO estimates the current global average salt intake to be $10 \mathrm{~g} /$ person per d but recommends a daily intake of no more than $5 \mathrm{~g} /$ person per $\mathrm{d}$ (approximately $2 \mathrm{~g} \mathrm{Na} / \mathrm{d})^{(28)}$. Salt is added to food in three main ways: during food processing, during food preparation and at the table. In 2013, South Africa and Argentina became the first jurisdictions to set mandatory limits for salt across a broad range of commonly consumed foods ${ }^{(9)}$. In the present paper, we document the policy process in South Africa as a case study of the development and implementation of mandatory salt limits. Given increasing interest in the use of mandatory nutrient limits for NCD prevention, there is scope for other jurisdictions to learn from South Africa's experience. The paper aims to inform global understanding of the development and implementation of innovative regulation for dietrelated disease, for countries wishing to take a similar approach.

The Republic of South Africa is a representative democracy and an 'upper middle income' country ${ }^{(29)}$. The population experiences wide disparities in socioeconomic and health status ${ }^{(30)}$. South Africa is described as having a 'quadruple burden of disease', with NCD occurring alongside infectious diseases, maternal and child mortality, and trauma ${ }^{(31)}$. In 2010, 38.9\% of deaths were attributable to $\mathrm{NCD}^{(32)}$ and the prevalence of hypertension in South Africa is $31 \%$ for men and $36 \%$ for women, with the prevalence in men doubling between 1998 and $2008^{(31,33)}$. The cause of this increase is multifactorial and includes the shift away from traditional staple foods and increasingly towards processed foods high in salt, characteristic of the nutrition transition ${ }^{(34,35)}$.

\section{Methods}

\section{Theoretical framework}

We analysed the development and enactment of the mandatory salt limits in South Africa using case study research methodology informed by regulatory studies and policy analysis frameworks ${ }^{(36-38)}$. In particular, we drew on Walt and Gilson's health policy analysis triangle, which provides an analytical framework for the collection and analysis of qualitative data related to policy development and reform ${ }^{(39,40)}$. Its components are the content, context and process of the policy (the apices of the triangle) and the actors involved (in the centre of the triangle). Into this framework we also incorporated considerations from the field of regulatory studies. This field provides insights into different regulatory forms (i.e. relevant to policy content), for instance traditional 'command-and-control' government regulation compared with voluntary or co-regulatory approaches ${ }^{(41-43)}$. This is important because of the increasing involvement of non-governmental actors in the food and public health policy arena, traditionally the domain of the state ${ }^{(44)}$. In addition, given the global context of diet-related NCD policy and the important role of inter-jurisdictional policy learning in this space ${ }^{(1)}$, we considered theories of policy learning, including the framing of the problem and the role played by institutions ${ }^{(45-47)}$.

\section{Data collection and analysis}

During March 2015, we reviewed the regulation and conducted interviews with stakeholders in Pretoria, Johannesburg and Cape Town (the three official cities of government in South Africa). We identified stakeholders to interview by mapping the key institutional actors involved in the policy process in South Africa, and by conducting informal or backgrounding interviews on the policy landscape for the salt regulation. Based on this, we sent letters of invitation to key policy makers, as well as members of two working groups, with relevance to the salt regulation. Initially, twelve interviews were requested; three people declined or were unavailable (one each from the industry, government and academic sectors). We gained additional interviewees through snowball sampling during interviews and completed interviews when no further potential interviewees were identified by participants.

We conducted ten interviews with stakeholders falling into four sectors: government ( $n$ 3), academia $(n 2)$, the food industry (n 3) and non-governmental organisations (NGO; $n 2$ ). All interviewees gave their written consent to be interviewed. The majority of the interviews were audio- 
recorded and transcribed later. In two cases, the interviews were not audio-recorded at the interviewees' request.

The interviews were semi-structured, with questions based on our theoretical frameworks. Specifically, questions included:

- Who initiated the regulations?

- How did the regulation get on the policy agenda?

- Were different policy options considered? Which ones? Why were these not pursued?

- Were international precedents considered?

- Once regulation was on the agenda, what did the development process involve? Who did it involve?

- How were the technical aspects (e.g. specific salt reduction targets) of the regulation determined?

- What are the benefits of the regulation? What are its burdens?

- Was the decision to legislate controversial? How was the issue framed in the media and other public discourse?

These questions were piloted in three backgrounding interviews, to assess the appropriateness of the questions asked. J.C.K. conducted all interviews, with H.S. in attendance for four of these. J.C.K. took detailed notes throughout all interviews and transcribed them immediately afterwards. We also asked the interviewees to provide relevant documentation to support or provide background for particular points made during the interview. This process yielded 'grey' literature including policy documents, research reports, briefs from advocacy organisations, and publicly available data such as the South African census information. We drew on this to triangulate our interview findings with respect to policy context, actors and process.

The data were analysed qualitatively, using the theoretical frameworks to guide hand-coding of the interview transcripts and extraction of relevant data from documents. J.C.K. led the analysis, which was reviewed and refined by A.M.T. and H.S. The coded data were used to construct a detailed narrative of the policy process, as well as to identify the actors and contextual factors that had shaped decision making and policy content, with reference to potential for policy learning in other jurisdictions. The Human Research Ethics Committee of the University of Sydney, Australia, approved the study (project number 2014/1000).

\section{Results}

\section{Policy content}

South Africa's mandatory salt limits were implemented via the 'Regulations relating to the reduction of sodium in certain foodstuffs and related matters', Regulation No. 214 under the Foodstuffs, Cosmetics and Disinfectants Act 1972 (hereafter, 'the Regulation'). The Regulation was signed into law in March 2013 by the national Minister of Health, Dr Aaron Motsoaledi. It covers thirteen product categories, which were required to comply with a first sodium limit by 30 June 2016, followed by a lower sodium limit by 30 June 2019 (Table 1). The Regulation also specifies two different methodologies for testing the amount of sodium in food: one for bread and another for all other products. The Regulation is purely technical in nature and does not mention hypertension, stroke or heart disease, or provide any other context.

\section{Context}

As Walt and Gilson emphasise, the historical and countryspecific context in which policy is developed is a critical factor shaping the outcome of that policy ${ }^{(39,40,48)}$.

Table 1 Extract from 'Regulations relating to the reduction of sodium in certain foodstuffs and related matters' (adapted from South African Government, $2013^{(77)}$ )

\begin{tabular}{|c|c|c|}
\hline Foodstuff category & $\begin{array}{l}\text { Maximum total } \\
\text { Na per } 100 \mathrm{~g} \\
\text { foodstuff }(\mathrm{mg})\end{array}$ & $\begin{array}{l}\text { Dates on which the } \\
\text { total sodium reduction } \\
\text { becomes effective }\end{array}$ \\
\hline Bread & $\begin{array}{l}400 \\
380\end{array}$ & $\begin{array}{l}30 \text { June } 2016 \\
30 \text { June } 2019\end{array}$ \\
\hline $\begin{array}{l}\text { All breakfast cereals and } \\
\text { porridges, whether } \\
\text { ready-to-eat, instant } \\
\text { or cook-up, hot or cold }\end{array}$ & $\begin{array}{l}500 \\
400\end{array}$ & $\begin{array}{l}30 \text { June } 2016 \\
30 \text { June } 2019\end{array}$ \\
\hline $\begin{array}{l}\text { All fat spreads and butter } \\
\text { spreads }\end{array}$ & $\begin{array}{l}550 \\
450\end{array}$ & $\begin{array}{l}30 \text { June } 2016 \\
30 \text { June } 2019\end{array}$ \\
\hline $\begin{array}{l}\text { Ready-to-eat savoury } \\
\text { snacks, excluding } \\
\text { salt-and-vinegar } \\
\text { flavoured savoury } \\
\text { snacks }\end{array}$ & $\begin{array}{l}800 \\
700\end{array}$ & $\begin{array}{l}30 \text { June } 2016 \\
30 \text { June } 2019\end{array}$ \\
\hline $\begin{array}{l}\text { Flavoured potato crisps, } \\
\text { excluding salt-and- } \\
\text { vinegar flavoured } \\
\text { potato crisps }\end{array}$ & $\begin{array}{l}650 \\
550\end{array}$ & $\begin{array}{l}30 \text { June } 2016 \\
30 \text { June } 2019\end{array}$ \\
\hline $\begin{array}{l}\text { Flavoured, ready-to-eat, } \\
\text { savoury snacks and } \\
\text { potato crisps - salt- } \\
\text { and-vinegar only }\end{array}$ & $\begin{array}{r}1000 \\
850\end{array}$ & $\begin{array}{l}30 \text { June } 2016 \\
30 \text { June } 2019\end{array}$ \\
\hline Processed meat (cured) & $\begin{array}{l}1300 \\
1150\end{array}$ & $\begin{array}{l}\text { 31 March } 2017 \\
\text { 30 June } 2019\end{array}$ \\
\hline $\begin{array}{l}\text { Processed meat } \\
\text { (uncured) }\end{array}$ & $\begin{array}{l}850 \\
650\end{array}$ & $\begin{array}{l}30 \text { June } 2016 \\
30 \text { June } 2019\end{array}$ \\
\hline $\begin{array}{l}\text { Raw-processed meat } \\
\text { sausages (all types) } \\
\text { and similar products }\end{array}$ & $\begin{array}{l}800 \\
600\end{array}$ & $\begin{array}{l}30 \text { June } 2016 \\
30 \text { June } 2019\end{array}$ \\
\hline $\begin{array}{l}\text { Dry soup powder (not } \\
\text { the instant type) }\end{array}$ & $\begin{array}{l}5500 \\
3500\end{array}$ & $\begin{array}{l}30 \text { June } 2016 \\
30 \text { June } 2019\end{array}$ \\
\hline $\begin{array}{l}\text { Dry soup powders and } \\
\text { dry instant savoury } \\
\text { sauces }\end{array}$ & $\begin{array}{l}3500 \\
1500\end{array}$ & $\begin{array}{l}30 \text { June } 2016 \\
30 \text { June } 2019\end{array}$ \\
\hline $\begin{array}{l}\text { Dry savoury powders } \\
\text { with dry instant } \\
\text { noodles to be mixed } \\
\text { with a liquid }\end{array}$ & $\begin{array}{r}1500 \\
800\end{array}$ & $\begin{array}{l}30 \text { June } 2016 \\
30 \text { June } 2019\end{array}$ \\
\hline $\begin{array}{l}\text { Stock cubes, stock } \\
\text { powders, stock } \\
\text { granules, stock } \\
\text { emulsions, stock } \\
\text { pastes or stock jellies }\end{array}$ & $\begin{array}{l}18000 \\
13000\end{array}$ & $\begin{array}{l}30 \text { June } 2016 \\
30 \text { June } 2019\end{array}$ \\
\hline
\end{tabular}


According to the interviewees, national as well as international factors provided the context for the Regulation. All interviewees described high and growing national rates of hypertension. They described the potent interaction between high dietary salt intakes and the genetic salt sensitivity of black South Africans (who make up $79.6 \%$ of the population ${ }^{(49,50)}$ ). Some interviewees noted that hypertension was a relatively new policy focus for South Africa, following decades of attention on infectious diseases (especially HIV) and undernutrition. Several interviewees made reference to the food selection constraints experienced by people on low incomes, with cost, rather than nutrition, being the main consideration. Low-income populations thus consume a limited diet, heavy in starch particularly refined white maize meal and brown bread. Interviewees also noted that cheap processed foods tended to be high in salt and that added salt was often the only thing that made such food flavoursome.

Interviewees noted that the national food-based dietary guidelines include the advice to 'use salt sparingly'. The guidelines have been in place since 2001, and this advice has since been updated to 'use salt and foods high in salt sparingly, (51). However, some interviewees expressed scepticism about the impact of the food-based dietary guidelines on the behaviour of either the food industry or individual citizens. On the contrary, they mentioned cultural beliefs and practices that ascribe positive characteristics to salt and which might therefore undermine official dietary advice. One interviewee stated: 'Culturally, salt is considered to be wealth ... if you don't have salt in the home, then you have a real problem.'

Interviewees in all stakeholder groups gave evidence that the international context, in which momentum on NCD was growing, was an influence on South Africa's national NCD policy. They suggested that while national epidemiological trends may have provided the context for action, international political factors explain the speed and forcefulness of that action. In September 2011, which according to interviewees was a critical time in the policy development stage, the UN General Assembly held its high-level meeting on the Prevention and Control of Noncommunicable Diseases (19-20 September 2011). In the lead-up to that meeting, the South African health minister had attended domestic and international summits on NCD and their prevention through policy. This international policy context contributed to a sense of urgency and a sense that action needed to be both swift and visible.

\section{Process}

If context explains why South Africa considered hypertension to be a priority problem, then process relates to how it came to be addressed in this specific way, i.e. regulating salt in processed foods. We focus on three phases of the policy process: agenda setting, development and implementation.

\section{Agenda setting}

Agenda setting refers to 'the issue sorting stage during which a small number of the many problems societies face rise to the attention of decision-makers ${ }^{(40)}$. We found two important factors that combined to get this particular policy option on the decision makers' agenda. First, new research findings by academics were presented to the Department of Health (DoH) in 2010, establishing the effectiveness of food supply interventions (i.e. the 'what' of this policy intervention). Second, there was a widespread perception among stakeholders that government regulation (and not self-regulation) would be the quickest and most effective way of addressing the identified problem (i.e. the 'how' of this policy intervention).

Establishing policy-relevant evidence was the first step in the agenda-setting phase. Many interviewees explained that the data linking salt consumption and hypertension are very complex and were in many cases unavailable for South Africa until recently. Interviewees stressed that multiple types of data were necessary to build the case for government intervention, as summarised in Table 2 . Together, these data acted as links in an evidentiary chain that provided impetus for action. Among these, interviewees identified an intervention study by Charlton et $a l .{ }^{(52)}$ as one of the most important links in the chain. They noted that Charlton and colleagues had demonstrated that adjusting the salt content of commonly consumed foods with high levels of salt could shift salt consumption in the study population.

Academic interviewees described the process of meeting with the DoH bureaucrats and explaining to them the significance of this research. Once they heard and understood the researchers' message, in 2010, it seems that the bureaucrats moved quickly from evidence to action. Having 'bought in' to the idea of a food supplybased intervention, the DoH bureaucrats secured the support of the Minister of Health and ultimately drove the regulatory agenda (discussed further under 'Development' below).

\section{Development}

Once the DoH decided to take action, it considered two main policy options: government regulation and industry

Table 2 Links in the evidentiary chain: different types of scientific evidence that contributed to regulatory action on salt in South Africa

- Evidence of the amount of salt consumed across South Africa, and within different population groups. Evidence of how salt was consumed (i.e. in processed foods or as discretionary salt). Evidence of which foods contributed to greatest salt intake ${ }^{(78)}$

- Food composition tables, showing the natural salt content of commonly-consumed foods

- Epidemiological data showing rates of hypertension

- Intervention studies (i.e. evidence that reducing salt consumption can reduce hypertension, such as the study by Charlton et al. ${ }^{(52)}$ )

- Health economic data about the relative cost of different interventions 
self-regulation (also described as 'voluntary' measures). However, government regulation was the preferred approach because of a widespread perception that it was the more effective option. Regardless of whether they supported government regulation or not, government and industry interviewees alike characterised it as the stronger, 'tough' or 'hard-hitting' option, which would yield results faster. The need for strong action was seen to be necessary for a variety of reasons. Some interviewees pointed to the diverse and uncoordinated nature of the South African food industry, with a high proportion of small and medium enterprises. These companies were perceived to be less likely to implement voluntary industry norms; as one person said, 'the companies operate on their own and they will do their own thing.' Others were suspicious that, under self-regulatory conditions, industry would make only minimal changes to salt levels. Further, the need for speedy action was explained by the international political context described above.

Interviews gave evidence that 'nanny state' debates, and concerns about the paternalistic nature of the regulation, were not an influential aspect of the issue's framing. Rather, interviewees across the groups stressed the more positive attributes of regulation, particularly its power to address the social determinants of high salt consumption. They argued that regulation could reach the whole population and create healthier environments, because it does not rely on individual behaviour change. As one NGO interviewee explained:

'By legislating it ... you're doing it already for the consumer: it's already done. Dietary guidelines, all of those [kinds of policies], leave it up to the individuals to make the changes, a lifestyle change. But the legislation forces it, it happens, that's it. And it's going to have an impact across the board.'

In 2010, the DoH began consulting with different stakeholders, including the food industry. We found the highest amount of disagreement among interviewees in relation to this part of the policy process. The main point of contention was whether or not the DoH had engaged in a truly consultative process. Industry interviewees felt that the outcome (i.e. regulation) was predetermined and the process too hasty. By contrast, government, NGO and academic interviewees all described the process as highly consultative.

The industry interviewees had all been involved in policy discussions from an early stage. They shared a common perception with the government interviewees that regulation was always an option if industry failed to take action on salt of its own accord. However, industry believed that this option of last resort was triggered too swiftly, and without adequate consultation or explanation. They felt they had been ambushed by regulation, describing a situation in which regulation quickly went from being only one of several options under consideration, to suddenly being rushed through. One industry interviewee stated: 'One moment we're still brainstorming and the next moment, there's a regulation!' Another said: 'The Minister signed off the new regulations, in the middle of a consultative process! ... Everybody thought that we were going to have another round or two of consultation, but that didn't happen.'

In contrast, government interviewees believed that they had engaged in a consultative process - but only to the extent necessary or appropriate. A senior DoH bureaucrat stated:

'We certainly realised that the industry were key players in this. But I wouldn't imagine that I would have called the industry until I had some ideas, first, about what we might want to do, and how we might want to engage with them. And we probably would have spoken to a couple of other stakeholders first, who had much more of a health interest in this, than a profit interest. And I think that that's quite legitimate, because we are a Health Department, and we need to look at how best to improve health.'

Government and NGO interviewees felt that industry had already had plenty of time to self-regulate but had failed to act. One pointed out that South Africa had had food-based dietary guidelines for 15 years, with no impact on food industry practices and food composition. Government interviewees felt that while regulation was not their first option, industry was not 'coming to the table' on health, and so they were left with no alternative but to regulate. Furthermore, government and NGO interviewees gave evidence that, far from being ambushed, food companies had in fact requested regulation at the outset of discussions, to ensure a 'level playing field' across the industry. Industry interviewees agreed that they were initially in favour of regulatory action but were unpleasantly surprised by what they perceived as tough limits and tight timelines in the draft Regulation, and subsequently became less supportive. Matters progressed swiftly between 2010 (when discussions began) and 2011 (when the Minister gave his support)

Once the course of action was confirmed, a senior bureaucrat within the Food Control Directorate of the South African DoH drafted the Regulation. As one government interviewee explained, it was simpler and quicker to implement the salt limits as regulations (i.e. delegated legislation) than to draft a new piece of legislation: it was a 'low-hanging fruit'. A draft Regulation was published in the government gazette in July 2012, with a three-month comment period ${ }^{(53)}$. During that time, government received submissions from at least twenty food industry companies and organisations. Food industry interviewees also stated that a 'pre-draft' was made available to them before the gazetted draft, as a courtesy. The main changes made between the draft and the final Regulation were that the later deadline was pushed back from 2018 to 2019, and 
there was some refinement of the food categories and testing methodologies.

\section{Implementation}

The Regulation was signed into law in March 2013, with the first salt reduction milestone at June 2016 and a subsequent one three years later. At the time of our interviews, industry stakeholders indicated that the milestones were technically feasible and that they were well on their way to achieving them, albeit with some cost as they had to make adjustments to machinery and ingredients. However, they predicted that the greatest threat to the effectiveness of the Regulation would be staffing and resource constraints for monitoring and enforcement. Separate from the Regulation, but supporting its implementation, a public awareness campaign called Salt Watch, led by the Heart and Stroke Foundation South Africa (an NGO), was launched to educate the population on the benefits of consuming less salt.

Like all health legislation in South Africa, the Regulation was set at the national level but will be enforced at the municipal level by local environmental health officers. Interviewees were concerned that the number and capacity of environmental health officers were limited, and that they shared laboratory space with forensic investigators, whose tests might take precedence. Furthermore, there is no single food regulator in South Africa. Several different bodies are involved: the DoH, the Department of Agriculture, Fisheries and Forestry, and the National Consumer Commission, each administering some food-related legislation, while two further standards setting agencies are responsible for food standards. Interviewees expressed concern that, as a result of this complexity, monitoring and enforcement of the Regulation would fall to companies monitoring one another and informing the authorities. Industry interviewees expressed frustration that this was essentially self-regulation by another name, with companies bearing the cost of monitoring in addition to implementation. They were concerned that the impact of such de facto self-regulation would be that big food companies would comply, while smaller operators ignored the new regulations and carried on business as usual.

Interviewees in all groups commented that, alongside the Regulation, health promotion and education would be vital to salt reduction in South Africa due to the high intake of discretionary salt ( $40 \%$ ). Although not part of the Regulation, interviewees regarded the Salt Watch campaign as being a key part of its implementation. This was due to a widely held view that, without education, people might simply add salt back in to salt-reduced products: 'Because even though there's legislation, without education, and getting discretionary salt down, you're not going to get impact. ... You've got to shift cultural beliefs by educating people.'

\section{Actors}

Interviewees gave evidence that the regulation was developed by a small and tight-knit policy community and was championed by a few key individuals. Stakeholders were in frequent contact and often 'wore many hats', i.e. they held many different roles simultaneously. Interviewees referred to each other by their first names, and many had moved between sectors during their careers. Many were members of the same handful of groups or institutions that were key to the Regulation. These included the Food Legislation Advisory Group (an informal body consisting of professional bodies and experts that consults to the Food Control Directorate within DoH) and the steering committee for Salt Watch. As such, many of the same people had been involved at all stages of the policy process, from formulating the regulations to implementing the health promotion campaign.

Interviewees pointed to the important leadership of particular individuals during the policy process. The Minister of Health and the top NCD bureaucrat were both portrayed as 'powerful', 'bold' 'champions' with 'vision' (as well as inflexible, 'dogmatic' and on a 'crusade'). Their persistence was seen as a critical in the Regulation's enactment. Another senior bureaucrat, within the Food Control Directorate, was repeatedly identified as the technical specialist who had designed the Regulation, as well as being the main gatekeeper of its interpretation and applicability to various foodstuffs. Many stakeholders also described the significant impact of an international public health expert, who had visited South Africa at least twice during the policy development process. Interviewees held mixed views towards this international expert: some commented on the value of international expertise, while others expressed concern about the influence of an international actor in the domestic policy space.

\section{Discussion}

The findings above suggest a high level of consensus among stakeholders that government regulation was the toughest and most effective approach to reducing salt consumption. Political and bureaucratic leadership, the international NCD policy environment, as well as robust scientific evidence, also played an important role in getting the Regulation enacted. Although the Regulation was developed in a consultative process, food industry stakeholders perceived this to be inadequate. Implementation is currently underway, supported by a health promotion programme, and stakeholders predict that monitoring and enforcement will be the most likely barriers to success.

Early analyses of the impact of the Regulation suggest that South Africa's mandatory salt limits are incentivising reformulation. Recent data suggest that two-thirds of foods covered by the Regulation have already met the limit during early stages of policy implementation, and that 
'only moderate reductions in sodium content will be required to bring many of the currently products in line with the regulation, ${ }^{(54)}$. This effectiveness evidence is necessary, but not sufficient, to influence policy change in other jurisdictions. Because politics is core to policy making ${ }^{(47)}$, understanding the policy process can enable other jurisdictions to move from evidence to action. The findings of the present study can inform public health advocacy and policy making in other jurisdictions wishing to implement a similar regulatory approach to population salt reduction.

\section{Learning from South Africa's innovative regulation for diet-related non-communicable diseases}

Drawing on theories of the policy process and regulatory theory, our findings highlight five potential lessons for other jurisdictions regarding the agenda setting and policy development processes undertaken in South Africa. In particular, these relate to: (i) considering existing policy tools in the design of the new policy measure; (ii) framing the use of strong policy tools in a positive way; (iii) coordinating the advocacy of public health actors; (iv) managing appropriate consultation and engagement with industry actors in the design of public health nutrition policy measures; and (v) ensuring enforcement capacity.

With respect to policy design, a key feature of the South African regulation was the pragmatic use of an existing policy instrument (the Foodstuffs, Cosmetics and Disinfectants Act 1972) to implement the intervention. Once a mandatory approach to salt reduction was decided upon, the choice to implement it using regulations, rather than legislation, was a significant enabler. Regulations tend to be more flexible than legislation and allow for drafting decisions to be made by those with technical expertise, rather than elected politicians. For this reason, they are particularly useful in policy areas where specifications are detailed and frequently changing, including food and health $^{(55,56)}$.

This meant that the development and passage of the Regulation was straightforward from a technical perspective, but also politically achievable. This was further reflected in what we found to be a lack of explicit framing of the Regulation as a 'nanny state' intervention. This finding was in direct contrast to way such regulations tend to be framed in the literature, where mandatory nutrient limits have been described as "highly paternalistic (57), 'controversial' (58), 'the most far-reaching form of limiting choice ${ }^{(59)}$ and 'some of the most contentious public health laws ${ }^{(60)}$. Framing is core to policy agenda setting, and effective frames can contribute to the opening of 'windows' for policy change ${ }^{(61,62)}$. In South Africa, the Regulation was framed as a strong and effective response to a situation requiring urgent action. It was clear from the interviews that the availability of local evidence underpinning this frame was powerful, as it: (i) demonstrated the high burden of hypertension; (ii) located the problem in the food supply, rather than in individuals (i.e. extremely high, and unnecessary, levels of salt in staple foods); and (iii) emphasised the limitations (education, poverty) faced by consumers in choosing 'healthier' diets, tying into a context of entrenched disadvantage in South Africa.

The NGO-led Salt Watch campaign created a platform for stakeholder coordination on salt as a public health issue. This helped to create a unified frame: (i) that salt was a policy issue; and (ii) that it required strong and urgent action. This reflected the role of strong 'advocacy coalitions' in supporting policy change ${ }^{(63,64)}$. In particular, this non-government platform created an opportunity for research evidence to inform advocacy, and the inclusion of food industry actors and bureaucrats on the board meant that all key stakeholders were familiar with the evidence for the problem of high salt intakes and policy options to address it, before the issue formally became the subject of policy discussion.

The work of Salt Watch and the local evidence for the severity of the problem were further supported by an institutional shift at the global level. In 2011, action on NCD became a focal area for the UN General Assembly (attended by the President), in addition to the World Health Assembly (attended by the Minister for Health). In the South African context, strong action on salt afforded an opportunity for the newly re-elected government to demonstrate commitment to tackling the high burden of NCD on the global stage. The leading NCD bureaucrat acted as a policy entrepreneur ${ }^{(62)}$, while the Minister was a political champion for strong action on salt. Strong political leadership has been identified as a critical element of successful national innovation on $\mathrm{NCD}^{(67)}$. In particular, the Minister's strong support gave the DoH confidence and the political capital it needed to implement the Regulation.

The present case study also highlights the fundamentally different beliefs of actors in different sectors about the appropriate role for industry in the development of nutrition policy. From the DoH's perspective, the purpose of consultation seemed to be to gain industry buy-in once regulation was already on the cards. By contrast, industry members believed that the purpose of consultation was to determine whether or not to pursue regulation at all. This contributed to a perception by some industry stakeholders that the outcome (i.e. regulation) was pre-ordained, and the process was not truly consultative. This speaks to a broader policy debate about whether, when, how and to what extent the food industry should have a seat at the table on nutrition policy. In relation to tobacco, the WHO is unequivocal that industry should play no role at any stage of the tobacco policy process ${ }^{(66)}$. However, in 
relation to food, the WHO has consistently used the language of 'responsible partnership' with industry ${ }^{(67-69)}$. And while some public health experts have stated that the food industry 'should have no role in the formation of national or international policy for non-communicable diseases ${ }^{,(70)}$, implementation is another matter. On this front, many would agree that the industry - as the producer of the food supply - does need to be part of the solution ${ }^{(71,72)}$.

Our findings suggest that while South Africa took appropriate steps to manage any potential conflict of interest, disparities between the perceptions of different stakeholders remained. A lesson for future policy making, therefore, is the importance of setting parameters, managing expectations, and clarifying early the precise nature and extent of industry's involvement. There is an important balance to be struck and guidance from the WHO Framework of Engagement with Non-State Actors may help countries to navigate this ${ }^{(73)}$.

Finally, the interviews revealed potential challenges for monitoring and enforcement, due to capacity limitations. As Burris and colleagues have argued, enacting a new law or regulation is only the first step of innovative public health regulation ${ }^{(74,75)}$. Implementation, monitoring, enforcement and analysis (especially useful for interjurisdictional policy learning) should be regarded as part of the process. For example, evaluating the success of the Regulation in achieving its goals - i.e. reducing dietary salt intake and hypertension - will be essential to policy learning. The case of South Africa suggests the need for policy makers to be aware of the need to consider, and build capacity for, these later steps at the same time that new regulatory interventions are being developed and implemented.

\section{Challenges and limitations}

The present study had two limitations, one relating to the interviewees and another to the timing of the research. First, certain key actors were not available to be interviewed, or were not able to be identified. As such, some important perspectives are likely to be missing. For example, the food industry interviewees all came from what might be described as Big Food, i.e. large corporations and trade organisations. These actors are well organised and well resourced, and thus may be able to implement the changes required by regulation more easily than smaller industry actors.

The second limitation of our research related to its timing. The interviews were conducted at a time when the Regulation had been passed but had not yet come into force. Industry interviewees were at an early stage of determining whether the salt limits and timelines would be feasible, and so could not report on that issue with certainty. Moreover, the lower limit does not come into force until 2019, so none of the interviewees could comment on the effectiveness of the Regulation.

\section{Conclusion}

Worldwide, there is growing interest in the use of legal and regulatory measures to improve the composition of the food supply and tackle diet-related $\mathrm{NCD}^{(76)}$. Mandatory nutrient limits are one such option, and South Africa has been a recent innovator on this front. While it is too early to assess its impact on population health outcomes, policy makers and the international public health community can learn from South Africa's experience of developing this policy. We reviewed the Regulation and conducted interviews with key stakeholders to the Regulation, representing the government, academia, food industry and NGO sectors. We analysed these data according to the health policy analysis triangle and regulatory theory, examining content, context, process and the actors involved. This systematic framework allowed us to identify lessons for other jurisdictions seeking to implement similar measures. Our findings suggest that jurisdictions should consider existing regulatory instruments when implementing otherwise-innovative policies, and should make a strong, positive case for the use of such instruments. Countries should also be alert to the need to manage stakeholder expectations around participation in policy development. Given the increasing interest in mandatory nutrient limits, there may also be a need for high-level policy guidance (e.g. from the WHO) on food industry participation in policy processes.

\section{Acknowledgements}

Acknowledgements: Roger Magnusson provided valuable guidance and feedback in the initial stages of this paper. Financial support: This paper will form part of J.C.K.'s $\mathrm{PhD}$ thesis, the research for which was funded through an Australian Postgraduate Award, as well as scholarships from Sydney Law School and the Charles Perkins Centre at the University of Sydney. H.S. thanks the Department of Science and Technology (DST)/National Research Foundation (NRF) South African Research Chairs Initiative (SARChl) in the National Development Plan Priority Area of Nutrition and Food Security (unique number SARCI170808259212) for support. The grant holders acknowledge that opinions, findings, and conclusions or recommendations expressed in any publication generated by the NRF-supported research are those of the author(s), and that the NRF accepts no liability whatsoever in this regard. Conflict of interest: None. Authorship: J.C.K. and A.M.T. devised the study. H.S. and J.C.K. identified the key stakeholders to be interviewed and conducted the initial engagement by sending letters to the stakeholders. J.C.K. and H.S. conducted the interviews. J.C.K, A.M.T. and H.S. analysed the data. J.C.K. led the writing of the paper, with all authors contributing. Ethics of human subject participation: This study was conducted according to the 
guidelines laid down in the Declaration of Helsinki and all procedures involving human subjects were approved by the Human Research Ethics Committee of the University of Sydney. Written informed consent was obtained from all subjects.

\section{References}

1. World Health Organization (2014) Global Status Report on Noncommunicable Diseases. Geneva: WHO.

2. World Cancer Research Fund International (2014) The Link Between Food, Nutrition, Diet and Non-Communicable Diseases - Why NCDs Need to be Considered When Addressing Major Nutritional Challenges. London: WCRF and The NCD Alliance.

3. World Health Organization (2013) Global Action Plan for the Prevention and Control of Noncommunicable Diseases 2013-2020. Geneva: WHO.

4. Hawkes C, Smith TG, Jewell J et al. (2015) Smart food policies for obesity prevention. Lancet 385, 2410-2421.

5. Garde A (2010) EU Law and Obesity Prevention. Alphen aan den Rijn: Kluwer Law International.

6. Roberto CA, Swinburn B, Hawkes C et al. (2015) Patchy progress on obesity prevention: emerging examples, entrenched barriers, and new thinking. Lancet 385, 2400-2409.

7. Hyseni L, Atkinson M, Bromley H et al. (2017) The effects of policy actions to improve population dietary patterns and prevent diet-related non-communicable diseases: scoping review. Eur J Clin Nutr 71, 694-711.

8. Hyseni L, Elliot-Green A, Lloyd-Williams F et al. (2017) Systematic review of dietary salt reduction policies: evidence for an effectiveness hierarchy? PLoS One 12, e0177535.

9. Webster J, Trieu K, Dunford E et al. (2014) Target salt 2025: a global overview of national programs to encourage the food industry to reduce salt in foods. Nutrients $\mathbf{6}$, 3274-3287.

10. Trieu K, Neal B, Hawkes C et al. (2015) Salt reduction initiatives around the world - a systematic review of progress towards the global target. PLoS One 10, e0130247.

11. Australian Government Department of Health (2017) Healthy Food Partnership. http://www.health.gov.au/internet/ main/publishing.nsf/Content/Healthy-Food-Partnership-Home (accessed March 2017)

12. European Commission DG Health and Food Safety (2017) EU platform for action on diet, physical activity and health. http://ec.europa.eu/health/nutrition_physical_activity/ platform_en (accessed March 2017).

13. Charlton K, Webster J \& Kowal P (2014) To legislate or not to legislate? A comparison of the UK and South African approaches to the development and implementation of salt reduction programs. Nutrients $\mathbf{6}, 3672-3695$.

14. He F, Brinsden H \& MacGregor G (2014) Salt reduction in the United Kingdom: a successful experiment in public health. J Hum Hypertens 28, 345-352.

15. Gilmore AB, Savell E \& Collin J (2011) Public health, corporations and the new responsibility deal: promoting partnerships with vectors of disease? J Public Health 33, 2-4.

16. Hawkes C \& Buse K (2011) Public health sector and food industry interaction: it's time to clarify the term 'partnership' and be honest about underlying interests. Eur J Public Health 21, 400-401.

17. Stuckler D \& Nestle M (2012) Big Food, food systems, and global health. PLoS Med 9, e1001242.

18. Panjwani C \& Caraher M (2014) The Public Health Responsibility Deal: brokering a deal for public health, but on whose terms? Health Policy 114, 163-173.
19. Elliott T, Trevena H, Sacks G et al. (2014) A systematic interim assessment of the Australian Government's Food and Health Dialogue. Med J Aust 200, 92-95.

20. Magnusson R \& Reeve B (2015) Food reformulation, responsive regulation, and 'regulatory scaffolding': strengthening performance of salt reduction programs in Australia and the United Kingdom. Nutrients 7, 5281-5308.

21. Jones A, Magnusson R, Swinburn B et al. (2016) Designing a Healthy Food Partnership: lessons from the Australian Food and Health Dialogue. BMC Public Health 16, 651-661.

22. Lloyd-Williams F, Bromley H, Orton L et al. (2014) Smorgasbord or symphony? Assessing public health nutrition policies across 30 European countries using a novel framework. BMC Public Health 14, 1195.

23. Kaldor JC (2018) What's wrong with mandatory nutrient limits? Rethinking dietary freedom, free markets and food reformulation. Public Health Ethics 11, 54-68.

24. Kaldor JC (2018) Food reformulation for NCD-prevention: regulatory options and potential barriers. QUT Law Rev 18, 76-95.

25. Downs SM, Thow AM \& Leeder SR (2013) The effectiveness of policies for reducing dietary trans fat: a systematic review of the evidence. Bull World Health Organ 91, 262-269.

26. Brownell KD \& Pomeranz JL (2014) The trans-fat ban food regulation and long-term health. $N$ Engl J Med 370, $1773-1775$.

27. World Cancer Research Fund International (2015) Curbing Global Sugar Consumption: Effective Food Policy Actions to Help Promote Healthy Diets and Tackle Obesity. London: WCRF International.

28. World Health Organization (2012) Guideline: Sodium intake for adults and children. http://www.who.int/ nutrition/publications/guidelines/sodium_intake_printver sion.pdf (accessed September 2018).

29. World Bank (2018) South Africa. https://data.worldbank. org/country/south-africa (accessed September 2018).

30. Statistics South Africa (2015) Poverty. http://www.statssa. gov.za/?page_id=739\&id=1 (accessed May 2015).

31. Berry KM, Parker WA, Mchiza ZJ et al. (2017) Quantifying unmet need for hypertension care in South Africa through a care cascade: evidence from the SANHANES, 2011-2012. BMJ Glob Health 2, e000348.

32. Nojilana B, Bradshaw D, Pillay-van Wyk V et al. (2016) Emerging trends in non-communicable disease mortality in South Africa, 1997-2010. S Afr Med J 106, 58.

33. Shisana O, Labadarios D, Rehle T et al. (2013) South African National Health and Nutrition Examination Survey (SANHANES-1). Cape Town: HSRC Press.

34. Pereira LM (2014) The Future of South Africa's Food System: What is Research Telling Us? South Africa: SA Food Lab.

35. Drewnowski A \& Popkin BM (1997) The nutrition transition: new trends in the global diet. Nutr Rev 55, 31-43.

36. Yin RK (2014) Case Study Research: Design and Methods. Los Angeles, CA: SAGE Publications, Inc.

37. Bell E (2010) Research for Health Policy. Oxford: Oxford University Press.

38. Thow AM, Annan R, Mensah L et al. (2014) Development, implementation and outcome of standards to restrict fatty meat in the food supply and prevent NCDs: learning from an innovative trade/food policy in Ghana. BMC Public Health 14, 249.

39. Walt G \& Gilson L (1994) Reforming the health sector in developing countries: the central role of policy analysis. Health Policy Plan 9, 353-370.

40. Walt G, Shiffman J, Schneider H et al. (2008) 'Doing' health policy analysis: methodological and conceptual reflections and challenges. Health Policy Plan 23, 308-317.

41. Black JM (1995) 'Which arrow?': rule type and regulatory policy. Public Law, 94-117. 
42. Black J (2002) Critical reflections on regulation. Aust J Legal Philos 27, 1-35.

43. Bartle I \& Vass P (2007) Self-regulation within the regulatory state: towards a new regulatory paradigm? Public Admin 85, 885-905.

44. Lang T, Barling D \& Caraher M (2009) Food Policy: Integrating Health, Environment and Society. Oxford/New York: Oxford University Press.

45. Rose R (1993) Lesson-Drawing in Public Policy: A Guide to Learning Across Time and Space. Chatham, NJ: Chatham House Publishers.

46. Dolowitz DP \& Marsh D (2000) Learning from abroad: the role of policy transfer in contemporary policy-making. Governance 13, 5-23.

47. Stone DA (2002) Policy Paradox: The Art of Political Decision Making. New York: Norton.

48. Buse K, Mays N \& Walt G (2012) Making Health Policy, 2nd ed. Maidenhead: McGraw-Hill Education.

49. Statistics South Africa (2012) Census 2011 - Census in Brief. Pretoria: Stats SA.

50. Wentzel-Viljoen E, Steyn K, Ketterer E et al. (2013) 'Use salt and foods high in salt sparingly': a food-based dietary guideline for South Africa. S Afr J Clin Nutr 23, 3 Suppl., S105-S113.

51. Vorster HH, Badham JB \& Venter CS (2013) An introduction to the revised food-based dietary guidelines for South Africa. S Afr J Clin Nutr 26, issue 3, S1-S164.

52. Charlton KE, Steyn K, Levitt NS et al. (2008) A food-based dietary strategy lowers blood pressure in a low socioeconomic setting: a randomised study in South Africa. Public Health Nutr 11, 1397-1406.

53. Republic of South Africa (2012) Regulation under the Foodstuffs, Cosmetics and Disinfectants Act 1972 (Act 54 of 1972), 'Regulations relating to the reduction of sodium in certain foodstuffs and related matters'; Draft, 11 July 2012. https://www.gov.za/sites/default/files/35509rg9787gon533. pdf (accessed November 2018).

54. Peters SAE, Dunford E, Ware LJ et al. (2017) The sodium content of processed foods in South Africa during the introduction of mandatory sodium limits. Nutrients 9, 404-419.

55. Fortin ND (2009) Food Regulation: Law, Science, Policy, and Practice. Hoboken, NJ: Wiley.

56. Vapnek J \& Spreij M (2005) Perspectives and Guidelines on Food Legislation, With a New Model Food Law. Rome: FAO.

57. Gostin LO (2008) Public Health Law - Power, Duty, Restraint, 2nd ed. Berkeley, CA: University of California Press.

58. Reynolds C (2011) Public and Environmental Health Law. Sydney: The Federation Press.

59. ten Have M, De Beaufort I, Teixeira P et al. (2011) Ethics and prevention of overweight and obesity: an inventory. Obes Rev 12, 669-679.

60. Taylor AL, Parento EW \& Schmidt L (2015) The increasing weight of regulation: countries combat the global obesity epidemic. Indiana Law J 90, 257-292.

61. Shiffman J \& Smith S (2007) Generation of political priority for global health initiatives: a framework and case study of maternal mortality. Lancet 370, 1370-1379.
62. Kingdon JW (1984) Agendas, Alternatives, and Public Policies. Boston, MA: Little, Brown.

63. Sabatier PA (1987) Knowledge, policy-oriented learning, and policy change: an advocacy coalition framework. Knowledge 8, 649-692.

64. Sabatier PA (1988) An advocacy coalition framework of policy change and the role of policy-oriented learning therein. Policy Sci 21, 129-168.

65. Magnusson RS \& Patterson D (2014) The role of law and governance reform in the global response to noncommunicable diseases. Global Health 10, 44-62.

66. World Health Organization (2003) Framework Convention on Tobacco Control, WHA56.1 (entered into force $27 \mathrm{Feb}$ ruary 2005). Geneva: WHO.

67. World Health Assembly (2013) Follow-up to the Political Declaration of the High-level Meeting of the General Assembly on the Prevention and Control of Noncommunicable Diseases (WHA66.10, 27 May 2013) (annexing the Global Action Plan for the Prevention and Control of Noncommunicable Diseases 2013-2020). Geneva: WHO.

68. World Health Organization (2004) Global Strategy on Diet, Physical Activity and Health. Geneva: WHO.

69. World Health Organization (2016) Report of the Commission on Ending Childhood Obesity (ECHO). Geneva: WHO.

70. Moodie R, Stuckler D, Monteiro C et al. (2013) Profits and pandemics: prevention of harmful effects of tobacco, alcohol, and ultra-processed food and drink industries. Lancet 381, 670-679.

71. Magnusson R \& Patterson D (2011) Role of law in global response to non-communicable diseases. Lancet $\mathbf{3 7 8}$, 859-860.

72. Stevenson MA (2015) The relevance of the public-private partnership paradigm to the prevention of diet-associated non-communicable diseases in wealthy countries. Glob Public Health 10, 930-946.

73. World Health Assembly (2016) Framework of Engagement with Non-State Actors. WHA6910. Geneva: WHO.

74. Burris S, Ashe M, Blanke D et al. (2016) Better health faster: the 5 essential public health law services. Public Health Rep 131, 747-753.

75. Burris S, Ashe M, Levin D et al. (2016) A transdisciplinary approach to public health law: the emerging practice of legal epidemiology. Annu Rev Public Health 37, 135-148.

76. Jewell J, Hawkes C \& Allen K (2013) Law and Obesity Prevention: Addressing Some Key Questions for the Public Health Community. London: WCRF International.

77. Republic of South Africa (2013) Regulation No. R. 214 under the Foodstuffs, Cosmetics and Disinfectants Act 1972 (Act 54 of 1972), 'Regulations relating to the reduction of sodium in certain foodstuffs and related matters'. http://extwprlegs1. fao.org/docs/pdf/saf122848.pdf (accessed November 2018).

78. Labadarios D, Steyn N, Maunder E et al. (2005) The National Food Consumption Survey (NFCS): South Africa, 1999. Public Health Nutr 8, 533-543. 